\title{
Comparative Study of Coumarin-120 (C-120) and Stilbine-3 (STB-3) Laser Dyes Doped in Sol-Gel Glasses
}

\author{
Laxman V. Jathar*, Milind Kulkarni, Dinesh Himatsinghani, Namrata Ajwani, Dilip G. Achalawat \\ Department of Physics, R. D. National College, Mumbai University, Mumbai, India \\ Email: ^laxmanjathar@gmail.com, achlawat.dilip@gmail.com, mjkulkarni@yahoo.co.in, dinesh.himatsinghani@gmail.com, \\ namrata.ajwani@gmail.com
}

How to cite this paper: Jathar, L.V., Kulkarni, M., Himatsinghani, D., Ajwani, N. and Achalawat, D.G. (2021) Comparative Study of Coumarin-120 (C-120) and Stilbine-3 (STB-3) Laser Dyes Doped in Sol-Gel Glasses. New Journal of Glass and Ceramics, 11, 57-82.

https://doi.org/10.4236/njgc.2021.113004

Received: February 14, 2021

Accepted: July 28, 2021

Published: July 31, 2021

Copyright $\odot 2021$ by author(s) and Scientific Research Publishing Inc. This work is licensed under the Creative Commons Attribution International License (CC BY 4.0).

http://creativecommons.org/licenses/by/4.0/ (c) (i) Open Access

\begin{abstract}
In 1967 the first work in solid state dye laser was performed by doping rhodamine dyes in Polymethylmethacrylate (PMMA) materials. Since then some materials like various types of polymers, co-polymers, poly composite glasses have been used as host matrices for doping different laser dyes. Polymers suffer from limited mechanical and thermal stability. Hence glasses can be the alternative hosts. However, because of high processing temperature leading to permanent destruction of dye molecules, the conventional glass preparation technique is not suitable for the introduction of organic laser dyes. This difficulty can be overcome by introducing the laser dye molecules in sol-gel glass which is prepared at low temperature. Recent work with sol-gel glasses shows that these glasses may prove to be better materials compared to polymeric materials because glasses being hard, best optically transparency in Near UV-UV and Visible region and show better photostability. In this research work we reported, comparative study of the photophysical properties of Coumarin-120 (C-120) belonging to 7-aminocoumarin family having two hydrogen atoms attached to the $\mathrm{N}$ atom at the 7-position, with Stilbene-3 (STB-3) in three types of $\mathrm{HCl}$ catalyzed $\mathrm{SiO}_{2}$ sol-gel matrices prepared by Method I, Method II and Method III respectively.
\end{abstract}

\section{Keywords}

Sol-Gel Glass, Laser Dye, Coumarin-120 (C-120), Stilbine-3 (STB-3)

\section{Introduction}

The first demonstration of dye laser was reported by Sorokin and Lankard in 1966 [1]. They observed stimulated emission from the alcoholic solution of 3,3' di- 
ethyltricarbocyanine dye excited by the intense pulse of giant ruby laser. Schafer, Schmidt and Marth were the first to report the dye laser operation in the visible and infrared region in 1967 [2]. Subsequently, Peterson first demonstrated a CW lasing action in Rhodamine 6G (Rh 6G) dye using Argon ion laser [3]. The development of newer and newer dye lasers has been always based on the discovery of new and better dyes. It was observed that when thousand dyes were tested for lasing action only four could give lasing action, out of which three belonging to the same series. There are various series of dyes such as Xanthene, Coumarin and Oxazine, etc. based upon the chromophore of the dye which are known to be efficient laser dye series [4] [5]. Although conventional dye lasers have a number of applications in the field of science, technology and medicine, but they do have some drawbacks also due to their liquid state. These conventional liquid dye lasers are commonly used in the solutions and need reservoirs, hoses, pumps, etc. to recirculate the colored solution in the cell or in the jet stream placed in the laser cavity. However, cumbersome system design, inflammable nature of solvent used, the toxicity of dye and solvent limit the applications of these lasers in particular field applications such as eye operation in hospital, chemical and mechanical industrial areas [5] [6] [7]. Entrapping laser dye molecules in transparent solid materials such as polymer, ceramic and porous glasses would eliminate many of these problems leading to the development of solid-state dye laser materials. The excellent properties such as high transparency, large porosity, high optical quality, good mechanical and thermal stability, and inert nature, etc. of sol-gel glass materials and advantages of processing technique over the conventional method of glass preparation have led to a number of applications of these materials in various fields of science and technology such as optical coatings, protective and porous films, dielectric and electronic coatings, window insulators reinforcement fibers, filters, high temperature superconductors, active waveguide, catalysts and host matrix for various type of biological and chemical dopants [8]-[22].

Coumarin-120 and Stilbene-3 (STB-3) laser dyes show very good photophysical properties in the blue-green region of the electromagnetic spectrum [23]-[62]. Many research works reported several coumarin and Stilebene-3 (STB-3) laser dyes in various solvents [23]-[47]. However, very few reports are available on photophysical properties of STB-3 in solid host matrices [51] [52]. To understanding and developing of solid state dye laser through the knowledge of photostability and cage environment effects on fundamental photophysical properties of laser dyes, which play a crucial role in lasing performance of dyes; we reported a comparative study between Spectroscopic properties of Coumarin-120 (C-120) and Stilbene-3 (STB-3) laser dyes doped in sol-gel host matrices using three distinct methods.

\section{Experimental}

\subsection{Molecular Structure}

\subsubsection{Molecular Structure of Coumarin-120 (C-120)}

Lambda Physik (Laser grade) Mol. wt. 231.30 
<smiles>[R]c1cc2c(C)cc(=O)oc2cc1N([R])[R]</smiles>

$$
\begin{array}{lllll} 
& \mathrm{R}_{1} & \mathrm{R}_{2} & \mathrm{R}_{3} \\
\mathrm{C} 1: & \text { Et } & \mathrm{Et} & \mathrm{H} \\
\mathrm{C} 2: & \text { Et } & \mathrm{H} & \mathrm{Me} \\
\mathrm{C} 120: & \mathrm{H} & \mathrm{H} & \mathrm{H}
\end{array}
$$

\section{Molecular structure of Coumarin-120 (C-120).}

\subsubsection{Molecular Structure of Stilbene-3 (STB-3)}

Stilbene 3 (STB3); Lambda Physik (Laser grade) Mol. wt. 562.62.

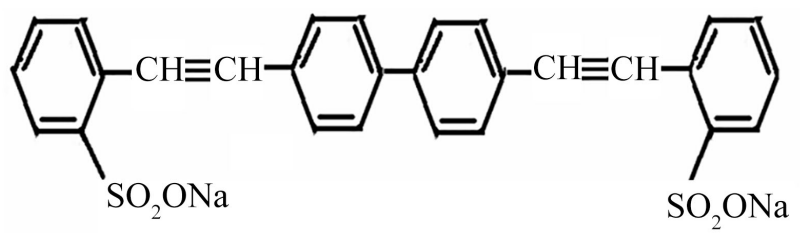

Molecular structure of Stilbene-3 (STB-3).

\subsection{Purification of the Materials}

Purity of the laser dyes was checked by UV-Visible absorption spectroscopy. The values of the extinction coefficient and absorption wavelength maximum of all the dyes were obtained by absorption measurements in methanol and the values were compared with the reported ones [53] [54] [55].

All the chemicals used for the preparation of sol-gel are of analytical grade. The solvents used for comparative study of dyes in liquid state are of GR grade. All the dyes and chemicals were used as received without further purification.

\subsection{Methods of Preparation of the Sol-Gel Materials}

The preparation of sol-gel glass samples is a two-step process involving hydrolysis and polycondensation of metal alkoxide in presence of a catalyst. The sol-gel materials are prepared in the present work by carrying out hydrolysis and poly condensation of Tetra Ethyl Ortho Silicate (TEOS) using $\mathrm{HCl}$ as catalyst.

The materials were prepared by employing three different methods.

1) Method I: using $\mathrm{HCl}$ as catalyst and glycerol as drying control chemical additive DCCA

A sol was prepared by mixing $11.2 \mathrm{ml}$ TEOS, $6 \mathrm{ml} \mathrm{MeOH}, 9 \mathrm{ml} \mathrm{H}_{2} \mathrm{O}, 1.0 \mathrm{ml}$ $\mathrm{HCl}(0.1 \mathrm{~N})$ as catalyst and $10 \mathrm{ml}$ glycerol as DCCA to reduce the cracking of monoliths during drying under magnetic stirring at room temperature. After 17 hours of stirring, $3.5 \mathrm{ml}$ sol was poured in the rectangular polystyrene cuvettes of size $(4.5 \times 1.0 \times 1.0) \mathrm{cm}^{3}$. The cuvettes were sealed with teflon tape to ensure slow drying of sol, which decreases the probability of cracking in solid. Drying and aging of gel were carried out at room temperature in clean and controlled environment. 
After about 45 days from the date of preparation, solid blocks were obtained in the form of parallelopipeds with dimensions $(0.8 \times 0.8 \times 2.0) \mathrm{cm}^{3}$. These glass samples were immersed in $\mathrm{MeOH} / \mathrm{H}_{2} \mathrm{O}$ (50:50 by volume) for 16 hours and then subsequently in $15 \mathrm{ml}$ methanolic solution of C-120 and STB-3 laser dye of known concentration for one hour. After removing the samples from the solution they were dried at room temperature. After 15 days of drying the surface of the samples gets dried so that it is handable and can be subjected to various measurements.

2) Method II: using $\mathrm{HCl}$ as catalyst at $60^{\circ} \mathrm{C}$ and drying at room temperature

A sol was prepared by mixing $78 \mathrm{ml}$ TEOS, $102 \mathrm{ml} \mathrm{H}_{2} \mathrm{O}, 2.4 \mathrm{ml} \mathrm{HCl}$ as catalyst under magnetic stirring at $60^{\circ} \mathrm{C}$ temperature for 1 hour. After 1 hour stirring, $3.5 \mathrm{ml}$ sol was poured in the rectangular polystyrene cuvettes and then sealed with teflon tape. Drying and aging of gel were carried out at room temperature in clean and controlled environment.

After about 20 days from the date of preparation, solid blocks were obtained in the form of parallelopipeds with dimensions $(0.8 \times 0.8 \times 2.8) \mathrm{cm}^{3}$. These glass samples were given dip treatment by immersing them in $\mathrm{MeOH} / \mathrm{H}_{2} \mathrm{O}$ (50:50 by volume) for different intervals of time such as 1 hour, 4 hours, 8 hours, 12 hours and 16 hours and then subsequently in methanolic solution of C-120 and STB-3 laser dye of known concentration for one hour. After removing the samples from the solution, they were dried at room temperature. After 5 days of drying the surface of the samples gets dried so that sample is handable and can be subjected to various measurements.

3) Method III: using $\mathrm{HCl}$ as catalyst at $60^{\circ} \mathrm{C}$ and heated at $600^{\circ} \mathrm{C}$ temperature for 3 hours

A sol was prepared by mixing $78 \mathrm{ml}$ TEOS, $102 \mathrm{ml} \mathrm{H}_{2} \mathrm{O}, 2.4 \mathrm{ml} \mathrm{HCl}$ as catalyst under magnetic stirring at $60^{\circ} \mathrm{C}$ temperature for 1 hour. After stirring, $3.5 \mathrm{ml} \mathrm{sol}$ was poured in the rectangular polystyrene cuvette and then sealed with teflon tape. Drying and aging of gel were carried out at $60^{\circ} \mathrm{C}$ temperature in heating blocks. After about 4 days from the date of preparation, solid blocks were obtained in the form of parallelopipeds with dimensions $(0.6 \times 0.6 \times 1.7) \mathrm{cm}^{3}$. These glass samples were given heat treatment by heating in programmable microwave furnace at $600^{\circ} \mathrm{C}$ for 3 hours and then subsequently they were cooled and kept at room temperature for one day and then the blocks were immersed separately in $15 \mathrm{ml}$ methanolic solution of C-120 and STB-3 dye of known concentration for one hour. After removing the samples from the solution, they were dried at room temperature. After 3 days of drying the surface of the samples gets dried so that it is handable and can be subjected to various measurements.

The number density of dye doped molecules in the solid host was calculated by difference method from the Optical Density (OD) of absorption of dye solution before and after dipping of the glass sample. The desired number density of 
dye molecules in solid host can be obtained by dipping of glass samples in varied concentration of methanolic solution of dye. The dried solids obtained by all the above methods were visually of good surface finish with plane parallel side faces. They were used directly for spectroscopic and laser studies without any polishing of the faces.

\subsection{Experimental/Instrumental Techniques}

\subsubsection{Absorption Spectroscopy Study}

Absorption/Transmission spectra of undoped glasses were recorded with air as reference and absorption spectra of dye-doped solids were recorded with undoped glass as reference. Absorption wavelength maximum $\left(\lambda_{a}\right)$ and molar absorptivity $(\varepsilon)$ of the dye in solid were determined and were compared with the respective properties in solution.

\subsubsection{Fluorescence Spectroscopy}

Fluorescence is a type of energy emission which is produced when a molecule returns to the ground state after having been raised to an excited state by absorption of energy. Fluorescence of the organic compounds is measured by fluorimeter. The experimental setup of a fluorimeter in our research laboratory is shown in Figure 1. It consists of a xenon lamp as an excitation source, an excitation monochromator, a sample compartment, an emission monochromator, a photomultiplier tube to detect signal, a photon counter and a XY/t recorder to get fluorescence spectrum or fluorescence data from photon counter can be stored in computer through Microprocessor Data Acquisition System (MIDAS). Fluorescence spectroscopy in the present study involves scanning of fluorescence spectra and measurement of fluorescence quantum yield. The fluorescence quantum yield of an emissive species is defined as the ratio of the number of emitted photons to the number of absorbed photons by the species. The two well known methods [56] for the measurement of fluorescence quantum yield value are given below:

\section{1) Transverse Method}

This method is used for optically dilute samples having optical density at $\lambda_{a}$ less than 0.1. In this geometry the excitation direction and detector are at right angles to each other as shown in Figure 2. Fluorescence spectra for the sample and reference are recorded by exciting them at appropriate wavelengths. Fluorescence spectra are corrected for monochromator and detector sensitivity. Fluorescence quantum yield of the sample is then calculated according to the formula:

$$
\varphi_{f s}=\left(\Delta_{f s} / \Delta_{a s}\right) *\left(\Delta_{a r} / \Delta_{f r}\right) *\left(n_{s}^{2} / n_{r}^{2}\right) * \varphi_{f r}
$$

where $\varphi_{f}$ is the fluorescence quantum yield,

$\Delta_{f}$ is the area under corrected curve for fluorescence spectrum,

$\Delta_{a}$ is the area under corrected curve for absorption spectrum,

$n$ is the refractive index; suffixes $\mathrm{s}$ and $\mathrm{r}$ are used to denote values for sample and reference respectively. 


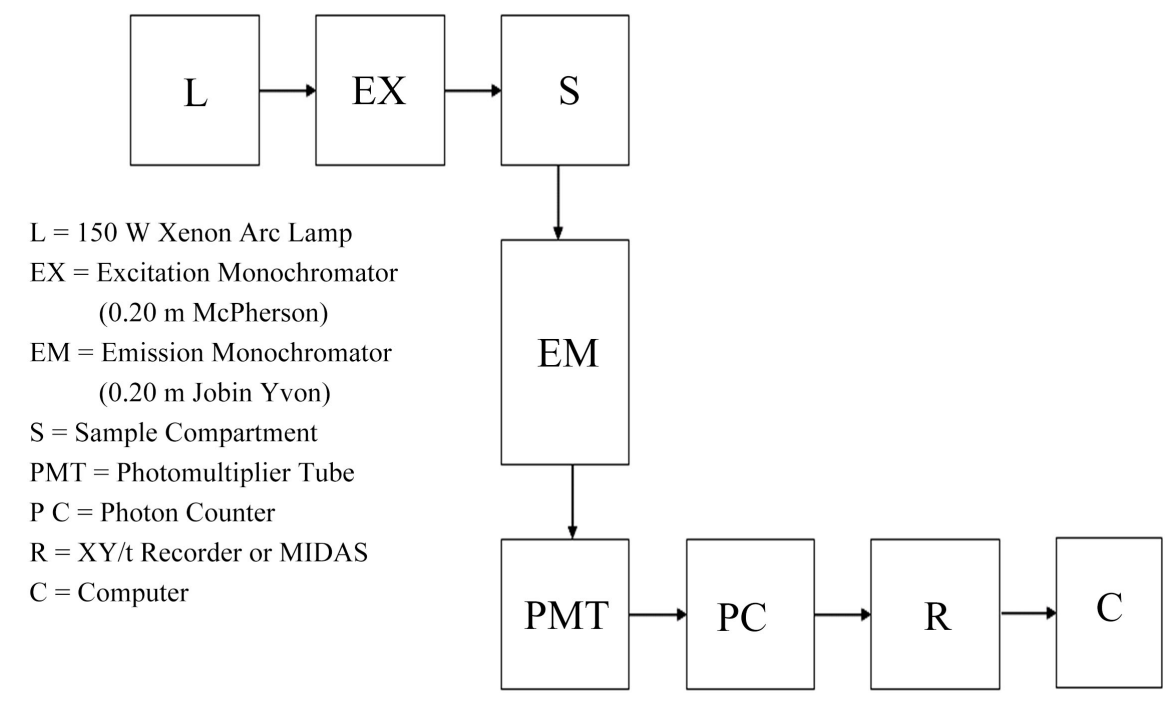

Figure 1. Fluorimeter.

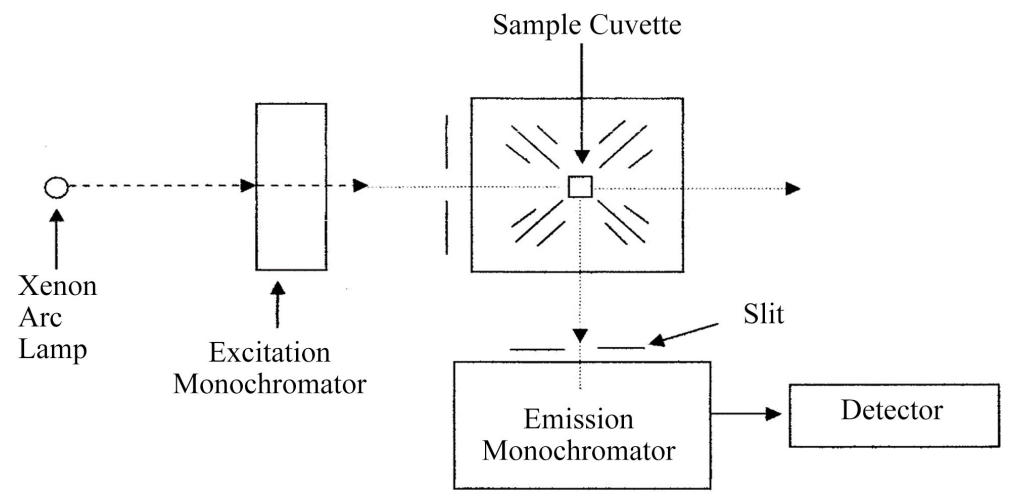

Figure 2. Excitation emission geometry in transverse method of fluorescence measurement.

\section{2) Front Surface Method}

This method is useful for the measurement of quantum yield with high dopant concentration. The concentration of dopant is normally selected so that $99 \%$ or more exciting light is absorbed in a first few millimeters of the sample. The experimental arrangement for the front surface geometry is shown in Figure 3. Fluorescence spectra for the sample and reference are recorded separately. Fluorescence spectra are corrected for monochromator and detector sensitivity. Fluorescence quantum yield of the sample is then calculated according to the formula:

$$
\varphi_{f s}=\left(\Delta_{f s} / \Delta_{a s}\right) *\left(\Delta_{a r} / \Delta_{f r}\right) *\left(n_{s}^{2} / n_{r}^{2}\right) * \varphi_{f r}
$$

In the present work, front surface excitation emission geometry is used for the fluorescence measurement of dye/sol-gel samples and dye in solution phase.

\subsubsection{Fluorescence Lifetime Measurement}

Fluorescence lifetime is defined as the average time interval between the absorption of exciting light and the emission of fluorescence by a molecule. It is typi- 
cally of the order of a few nanoseconds. There are mainly two methods used for the measurement of fluorescence lifetime, namely the pulse method and phase modulation. Pulse method can be of two types, direct method and indirect method. Direct method involves single pulse measurement by storage oscilloscope or Streak camera, while indirect measurement is the single photon counting technique [4]. In the present work, an indirect method known as single photon counting technique is used for the measurement of fluorescence lifetime. The experimental setup is shown in Figure 4. The principle involved in this method is the measurement of time interval between excitation pulse and the arrival of first photon at the detector.

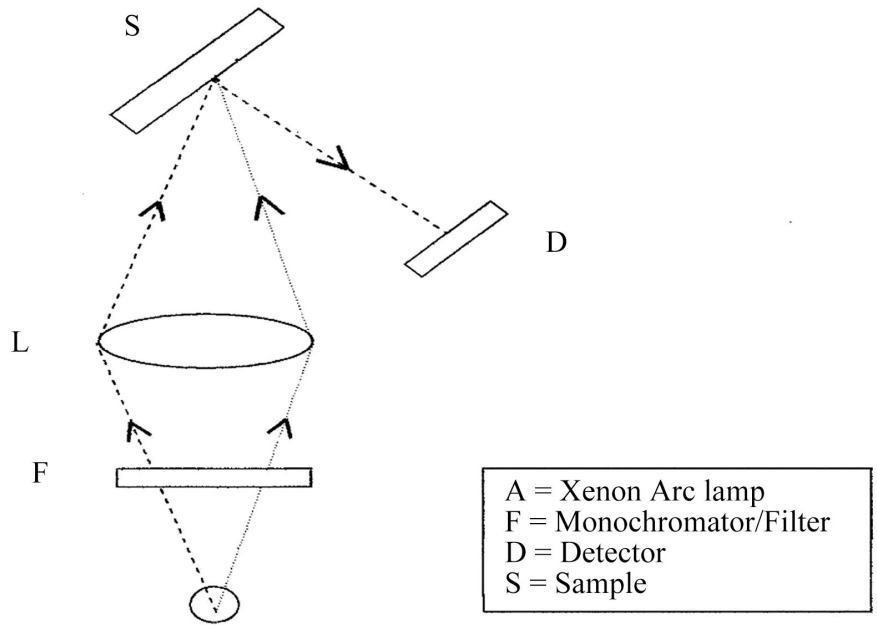

A

Figure 3. Excitation emission geometry in front surface method of fluorescence measurement.

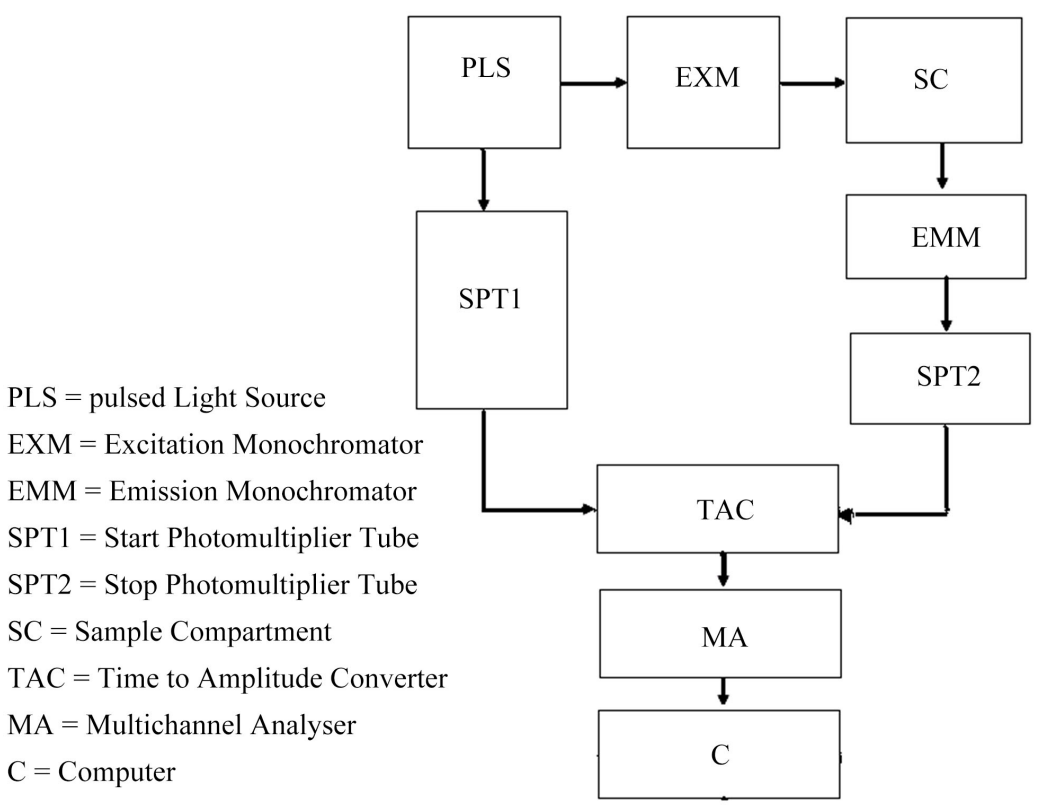

Figure 4. Time correlated single photon fluorimeter. 
Fluorescence lifetime of dye/sol-gel samples are measured on the model SP-80 nanosecond fluorescence spectrometer by using single photon counting technique. The experimental set-up consists of flashlamp (hydrogen filling at 0.5 atm) with $100 \mathrm{kHz}$ frequency, as excitation source, excitation/emission monochromators, start and stop photomultipliers, time to amplitude converter, multichannel analyzer and a computer. The deconvolution technique has been used to find lifetime value. They are single exponential decay with chi square value from 0.9 to 1.1 .

\section{Results and Discussion}

\subsection{Absorption/Fluorescence Properties of C-120}

The absorption and fluorescence spectra of C-120 dye doped sol-gel glass samples prepared by Method I, Method II and Method III are shown in Figures 5(a)-(c) and Figures 6(a)-(c) respectively with increasing drying time from the time of dipping of the sample in dye solution. It represents the typical behaviour of these solids which is observed for all the concentrations of the dye molecules studied in the present work as shown in Table 1 and Table 2.

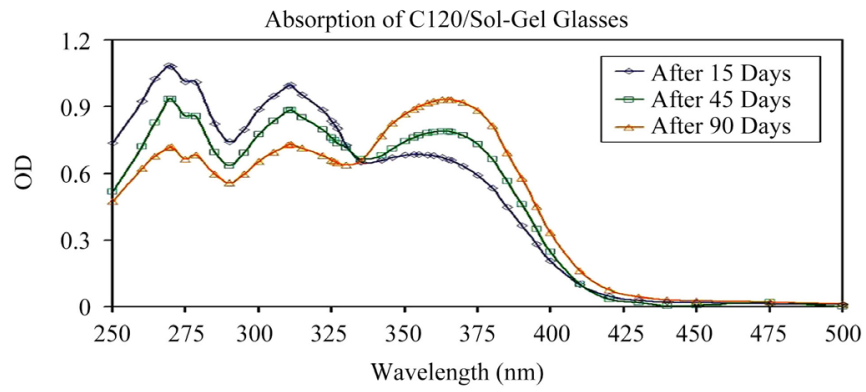

(a)

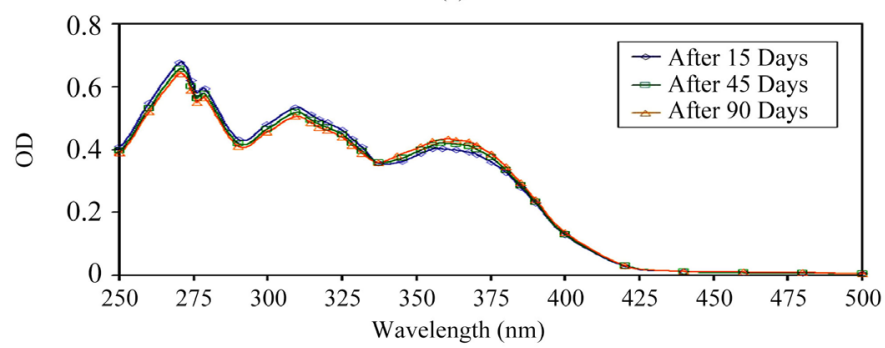

(b)

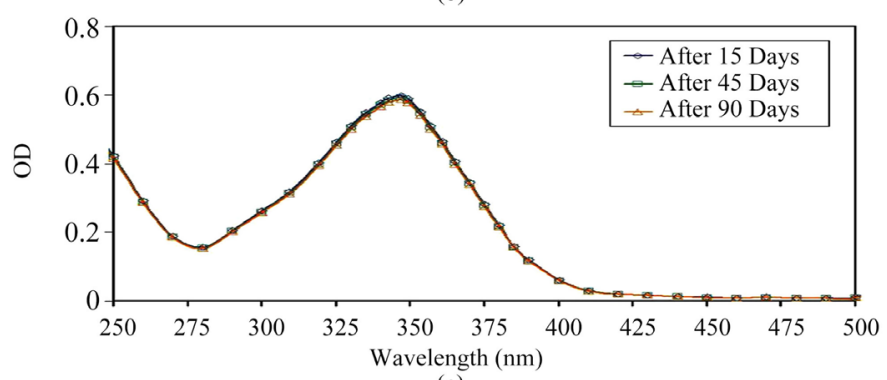

(c)

Figure 5. Absorption spectra of C-120 containing sol-gel glass sample. (a) Method I (no. density $9.78 \times 10^{16}$ per $\mathrm{cm}^{3}$ ), (b) Method II (no. density $5.20 \times 10^{16}$ per $\mathrm{cm}^{3}$ ) and (c) Method III (no. density $3.58 \times 10^{16}$ per $\mathrm{cm}^{3}$ ). 


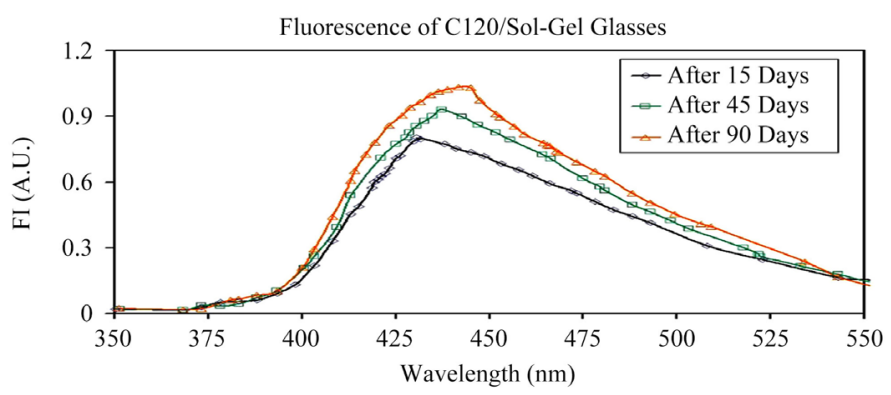

(a)

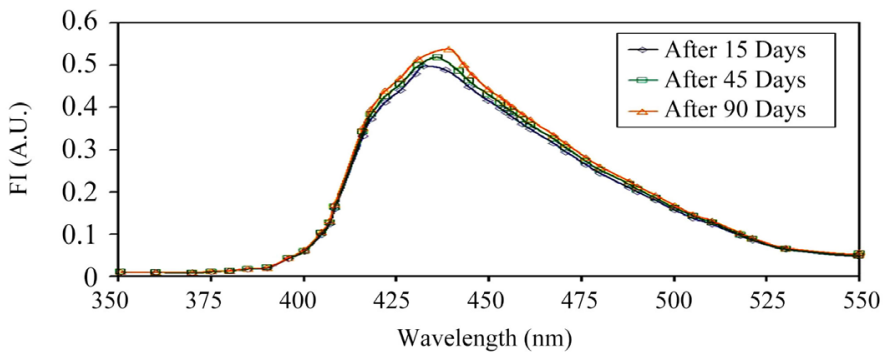

(b)

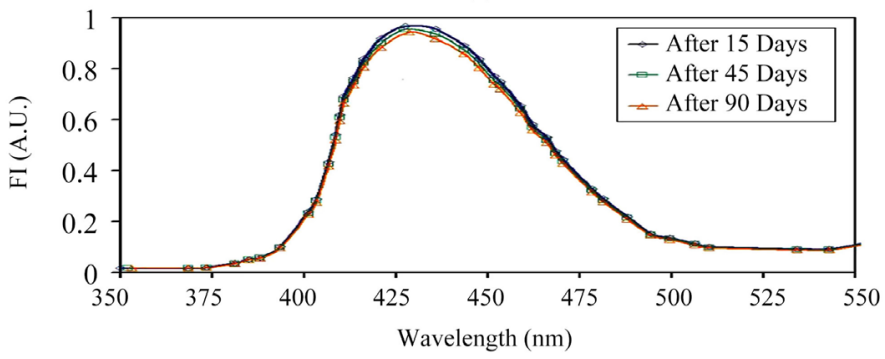

(c)

Figure 6. Fluorescence spectra of C-120 containing sol-gel glass samples. (a) Method I (no. density: $2.57 \times 10^{17}$ per $\mathrm{cm}^{3}$ ); (b) Method II (no. density: $7.18 \times 10^{17}$ per $\mathrm{cm}^{3}$ ) and (c) Method III (no. density: $3.42 \times 10^{17}$ per $\mathrm{cm}^{3}$ ).

Table 1. Absorption properties of C-120 containing sol-gel glass samples with concentration of dye.

\begin{tabular}{ccccc}
\hline C120/sol-gel glass (after 15 days drying) & $\lambda_{a}(\mathrm{~nm})$ & \multicolumn{3}{c}{ OD } \\
\hline No. Density per cm $\mathrm{cm}^{3}$ & & $6.51 \times 10^{16}$ & $1.77 \times 10^{17}$ & $3.45 \times 10^{18}$ \\
\hline & 354 & 0.41 & 0.68 & 1.95 \\
I & 311 & 0.60 & 0.99 & 2.40 \\
Method I & 278 & 0.63 & 1.00 & 2.50 \\
& 269 & 0.65 & 1.08 & 2.65 \\
\hline No. Density per cm & & $7.45 \times 10^{16}$ & $4.36 \times 10^{17}$ & $2.54 \times 10^{18}$ \\
\hline & 355 & 0.62 & 0.99 & 1.81 \\
I & 311 & 0.83 & 1.52 & 2.41 \\
Method II & 278 & 1.22 & 2.28 & 2.91 \\
& 269 & 1.29 & 2.58 & 2.98 \\
\hline No. Density per cm & & $1.48 \times 10^{15}$ & $2.13 \times 10^{16}$ & $3.21 \times 10^{17}$ \\
\hline & 350 & 0.24 & 2.21 & 3.00 \\
I Method III & 311 & 0.04 & 0.40 & 0.85 \\
& 278 & 0.05 & 0.55 & 1.09 \\
& 269 & 0.06 & 0.62 & 1.25 \\
\hline
\end{tabular}

Uncertainty $1 \mathrm{~nm}$ in $\left(\lambda_{a}\right) ; 0.05$ in (OD). 
Table 2. Fluorescence properties of C-120 containing sol-gel glass samples with concentration of dye.

\begin{tabular}{ccccc}
\hline $\begin{array}{c}\text { C120/sol-gel glass } \\
\text { (after 15 days drying) }\end{array}$ & $\lambda_{f}(\mathrm{~nm})$ & \multicolumn{3}{c}{ FI (A.U.) } \\
\hline No. Density per cm ${ }^{3}$ & & $6.51 \times 10^{16}$ & $1.77 \times 10^{17}$ & $3.45 \times 10^{18}$ \\
\hline Method I & 430 & 0.48 & 0.80 & 0.58 \\
\hline No. Density per cm ${ }^{3}$ & & $7.45 \times 10^{16}$ & $4.36 \times 10^{17}$ & $2.54 \times 10^{18}$ \\
\hline Method II & 432 & 0.62 & 0.87 & 0.54 \\
\hline No. Density per cm ${ }^{3}$ & & $1.48 \times 10^{15}$ & $2.13 \times 10^{16}$ & $3.21 \times 10^{17}$ \\
\hline Method III & 427 & 0.2 & 0.74 & 0.92 \\
\hline
\end{tabular}

Uncertainty $1 \mathrm{~nm}$ in $\left(\lambda_{f}\right) ; 0.05 \mathrm{in}(\mathrm{FI})$.

All C-120 doped solid glass samples prepared by method I and II having number densities of the order of $10^{16} / \mathrm{cm}^{3}$ to $10^{18} / \mathrm{cm}^{3}$ show four prominent absorption peaks peaking at $269 \mathrm{~nm}, 277 \mathrm{~nm}, 311 \mathrm{~nm}$ and $354 \mathrm{~nm}$ after 15 days of drying. As the drying time increases there is an increase in the OD value of longest absorption peak ( $354 \mathrm{~nm}$ for Method I and $355 \mathrm{~nm}$ for Method II) as can be seen from Figure 5(a), Figure 5(b). Absorption wavelength is also shifted from $354 \mathrm{~nm}$ to $366 \mathrm{~nm}$ and $355 \mathrm{~nm}$ to $361 \mathrm{~nm}$ region of Method I and Method II samples respectively with time of drying. For the lower concentration of the dye clear cut peak does not appear at $354 \mathrm{~nm}$ region but it starts appearing at a slightly shifted wavelength as the drying time increases. At the same time the OD at $311 \mathrm{~nm}, 277 \mathrm{~nm}$ and $269 \mathrm{~nm}$ are found to decrease with increasing drying time for the samples prepared by method I and II. In case of samples prepared by Method III, only single absorption peak at $350 \mathrm{~nm}$ is observed with no change in its OD value as drying time increases. On the other hand, the fluorescence spectra of all the C-120 dye doped sol-gel glass samples have single emission peak peaking at $430 \mathrm{~nm}, 432 \mathrm{~nm}$ and $427 \mathrm{~nm}$ for samples prepared by Method I, II and Method III respectively.

The fluorescence intensity also increases with time of drying accompanied by wavelength shift from ( $430 \mathrm{~nm}$ to $445 \mathrm{~nm}$ ) and ( $432 \mathrm{~nm}$ to $441 \mathrm{~nm}$ ) for all the concentrations of dye molecules studied for samples prepared by Method I and II respectively, while negligible change in fluorescence intensity is observed in samples prepared by Method III for the dye as the drying time increases as shown in Figures 6(a)-(c). However the observed changes in absorption and fluorescence properties with increasing drying time are very less in samples prepared by Method II as compared to samples prepared by Method I.

There was another experiment performed for samples prepared by Method II in which the dipping time in $\mathrm{H}_{2} \mathrm{O}: \mathrm{MeOH}$ is varied from 1 to 16 hours before the sample is dipped in dye solution. The effect of this treatment on absorption and fluorescence properties is studied. For these samples as the dipping time increases there is an increase in the OD value of main absorption peak at longest 
wavelength $(355 \mathrm{~nm})$, accompanied by slight red shift $(8 \mathrm{~nm})$ as can be seen from Figure 7(a). The Fluorescence Intensity (FI) also increase with time of dipping accompanied by red shift $(8 \mathrm{~nm})$ for C-120 embedded sol-gel glass samples prepared by method II as shown in Figure 7(b).

These changes are very favourable as the species absorbing around 350 - 365 $\mathrm{nm}$ are the neutral monomer species of the C-120 samples in sol-gel glasses which are fluorescent peaking at $430-445 \mathrm{~nm}$ and increase in the concentration of these monomer species increases the possibility of the samples to be laser active in the dye laser cavity.

To understand this behavior of C-120 doped sol-gel glass samples with drying time, absorption/fluorescence spectra of C-120 dye were recorded in methanol solution in the presence of $\mathrm{HCl}$ acid. When $\mathrm{HCl}$ is added to the methanolic solution of C-120 dye, it shows similar absorption as those of solid dried samples containing C-120 dye prepared by Method I and II as seen in Figure 7(a), Figure 7(b). Pure methanolic solution of C-120 shows only one absorption and fluorescence peak at $352 \mathrm{~nm}$ and $429 \mathrm{~nm}$ respectively, as shown in Figure 8(a), Figure 8 (b). OD at $352 \mathrm{~nm}$ peak decreases as the concentration of acid in solution

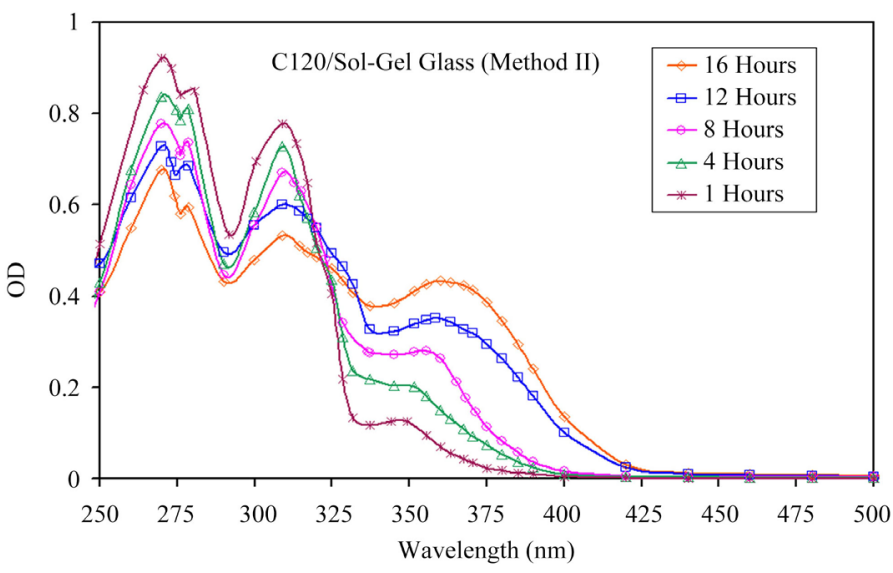

(a)

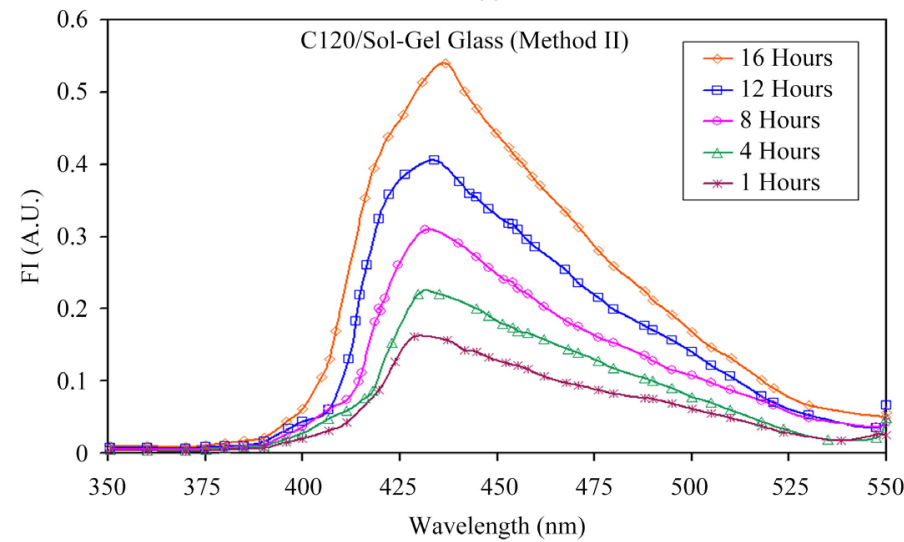

(b)

Figure 7. Absorption/Fluorescence spectra of C-120 containing sol-gel glass samples with dipping time of sample in $\mathrm{MeOH} / \mathrm{H}_{2} \mathrm{O}$ for Method II (a) Absorption and (b) Fluorescence (no. density $5.25 \times 10^{16}$ per $\mathrm{cm}^{3}$ ). 


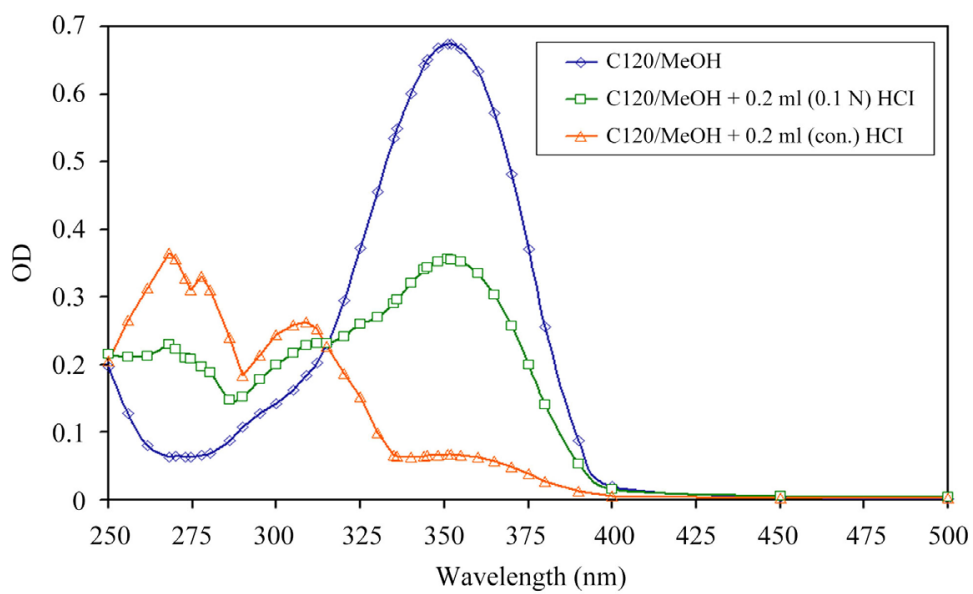

(a)

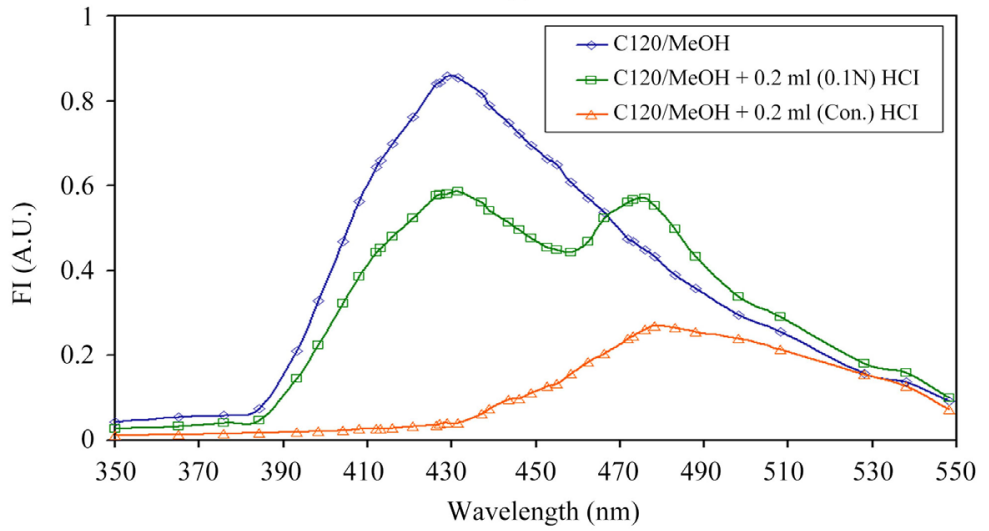

(b)

Figure 8. Absorption/Fluorescence spectra of $\mathrm{C}-120$ with addition of $\mathrm{HCl}$ for concentration of dye C-120 $\left(2.81 \times 10^{-5} \mathrm{~mol} \cdot \mathrm{l}^{-1}\right)$ (a) Absorption and (b) Fluorescence.

increases. This is accompanied by three more peaks appearing at shorter wavelengths viz $311 \mathrm{~nm}, 278 \mathrm{~nm}$ and $269 \mathrm{~nm}$. Their shapes are similar to their respective counterparts in solid sol-gel glass samples prepared by method I and II. These peaks are not due to absorption of $\mathrm{HCl}$ at lower wavelengths because they are absent in case of undoped samples though all the solids contain equal concentration of acid. The fluorescence maximum in solution is initially constant at about $429 \mathrm{~nm}$, only the fluorescence intensity decreases as the amount of acid in solution increases. Fluorescence at longer wavelength, namely $478 \mathrm{~nm}$ starts appearing at moderate acid concentrations only. At intermediate concentration of acid both peaks appear in the emission spectrum and finally only a single peak at $478 \mathrm{~nm}$ with diminished intensity is observed (Figure 8(b)).

As the drying time of sol-gel samples (Method I and II) and dipping time of sol-gel samples (Method II) dipped in $\mathrm{MeOH} / \mathrm{H}_{2} \mathrm{O}$ increases the absorption spectra of dried sol-gel glass samples resemble to the spectra of C-120 methanolic solution containing $\mathrm{HCl}$ acid. From the Figure 8(a) it can also be seen that there exists an isobestic point indicating that the increase in one peak is at the loss of OD at the other peak. This confirms the conversion of monomer species into some other species, probably protonated species. Table 3 and Table 4 presents 
the changes in the absorption and fluorescence properties of the C-120 dye in the sol-gel glass blocks with drying time prepared by the three methods respectively.

The parameter listed in Table 3 and Table 4 are absorption wavelength maximum $\left(\lambda_{a}\right)$, extinction coefficient $(\varepsilon)$ and fluorescence wavelength maximum $\left(\lambda_{f}\right)$, fluorescence quantum yield $\left(\Phi_{f}\right)$, lifetime of fluorescence $\left(\tau_{f}\right)$ and nonradiative deactivation rate constant (Knr). It can be seen that the absorption and fluorescence wavelengths of C-120 dye at main peak are slightly red shifted with time for all the samples. The change in extinction coefficient of C-120/sol-gel glasses at the longest absorption peak is least for Method III samples compared to Method I and Method II samples. The $\varepsilon$ value of C-120 dye for Method III samples is same as that of its methanolic solution. The $\Phi_{f}$ value is less in Method I and Method II samples because of the formation of non-emitting protonated species, as can be inferred from their absorption/fluorescence spectra, which further gets reduced on drying.

Compared to Method I, Method II samples Method III samples show less change in absorption/fluorescence properties with time and value of $\Phi_{f}$ is observed to be maximum in these samples. This value of $\Phi_{f}$ is nearly same as compared to that in $\mathrm{MeOH}$. While $\tau_{f}$ is short in Method I and Method II samples compared to Method III samples but small increase in value of $\tau_{f}$ with time as expected as the fluorescent monomer species increase with the time of drying. But in Method III samples the fluorescence lifetime values are quite large with

Table 3. Changes in absorption properties of C-120/sol-gel glass solids with drying time in comparison with $\mathrm{C}-120 / \mathrm{MeOH}$.

\begin{tabular}{|c|c|c|c|c|}
\hline \multirow{2}{*}{$\mathrm{C}-120 / \mathrm{MeOH}$} & \multicolumn{2}{|c|}{$\lambda_{a}$ at main peak $(\mathrm{nm})$} & \multicolumn{2}{|c|}{$\varepsilon \times 10^{-4}\left(1 \cdot \mathrm{mole}^{-1} \cdot \mathrm{cm}^{-1}\right)$} \\
\hline & a & $\mathrm{b}$ & $\mathrm{a}$ & $\mathrm{b}$ \\
\hline Method I & 354 & 366 & 0.766 & 1.051 \\
\hline Method II & 355 & 361 & 0.628 & 0.652 \\
\hline Method III & 350 & 350 & 1.675 & 1.669 \\
\hline
\end{tabular}

Uncertainty $1 \mathrm{~nm}$ in $\left(\lambda_{a}\right)$. a: Values after 15 days. b: Values after 90 days.

Table 4. Changes in fluorescence properties of C-120/sol-gel glass solids drying with time in comparison with $\mathrm{C}-120 / \mathrm{MeOH}$.

\begin{tabular}{|c|c|c|c|c|c|c|c|c|}
\hline \multirow{2}{*}{$\mathrm{C}-120 / \mathrm{MeOH}$} & \multicolumn{2}{|c|}{$\begin{array}{c}\lambda_{f}(\mathrm{~nm}) \\
429\end{array}$} & \multicolumn{2}{|c|}{$\begin{array}{c}\Phi_{f} \\
0.95\end{array}$} & \multicolumn{2}{|c|}{$\begin{array}{c}\tau_{f}(\mathrm{~ns}) \\
4.40\end{array}$} & \multicolumn{2}{|c|}{$\begin{array}{c}K_{n r} \times 10^{9} \\
0.011\end{array}$} \\
\hline & a & $\mathrm{b}$ & $\mathrm{a}$ & $\mathrm{b}$ & a & $\mathrm{b}$ & a & $\mathrm{b}$ \\
\hline Method I & 430 & 445 & 0.54 & 0.68 & 2.45 & 2.92 & 0.187 & 0.109 \\
\hline Method II & 432 & 439 & 0.48 & 0.51 & 2.64 & 2.65 & 0.197 & 0.185 \\
\hline Method III & 427 & 428 & 0.92 & 0.91 & 4.51 & 4.49 & 0.018 & 0.020 \\
\hline
\end{tabular}

Uncertainty $1 \mathrm{~nm}$ in $\left(\lambda_{f}\right) ; 0.05 \mathrm{in}\left(\Phi_{f}\right), 0.05 \mathrm{~ns}$ in $\left(\tau_{f}\right)$. a: Values after 15 days. b: Values after 90 days. 
almost no change in value with drying time. This shows that the nonradiative deactivation rate is maximum in Method I and Method II samples due to greater protonation as explained earlier which goes on decreasing after drying and it is least in Method III samples. The fluorescence quantum yield $\left(\Phi_{f}\right)$, lifetime of fluorescence $\left(\tau_{f}\right)$ and nonradiative deactivation rate constant (Knr) of C-120/ sol-gel glass solids prepared by Method III are found to remain almost unchanged after a period of 90 days.

This behaviour of C-120 dye can be explained by considering the ground state and excited state equilibria of the dye in the presence of acid as reported earlier by Drexhage [57]. These are depicted in Figure 9(a), Figure 9(b). The ground state of C-120 is represented by non-polar form (Figure 9(a)) which absorbs at $352 \mathrm{~nm}$. As mentioned earlier, in excited state C-120 predominantly exists in polar form (Figure 9(b)) which emits at $429 \mathrm{~nm}$. Being polar in excited state the carbonyl group has greater affinity towards proton. On the contrary, in the ground state basicity is associated with amino group. On addition of strong acid like $\mathrm{HCl}$ this amino group gets protonated.

This protonated form does not absorb at $352 \mathrm{~nm}$ hence the OD decreases [57]. The protonation increases with the acid concentration and the OD at $352 \mathrm{~nm}$ goes on decreasing. At the higher concentration of acid in addition to this protonated form two more species (may be higher protonated forms) are observed at lower wavelengths $(311 \mathrm{~nm}, 279 \mathrm{~nm}$ and $270 \mathrm{~nm})$. When excited at these wavelengths they were found to be non-emitting species.

Due to proton transfer from surrounding solvent molecules to the carbonyl group in excited state (Figure 9(b)) the fluorescence shifts towards green, namely at $478 \mathrm{~nm}$. The shift of fluorescence is observed clearly in solution phase. R. Srinivasan [26] has reported that when one or two drops of hydrochloric acid are added to the methanolic solution of coumarin 120, the fluorescence of C-120

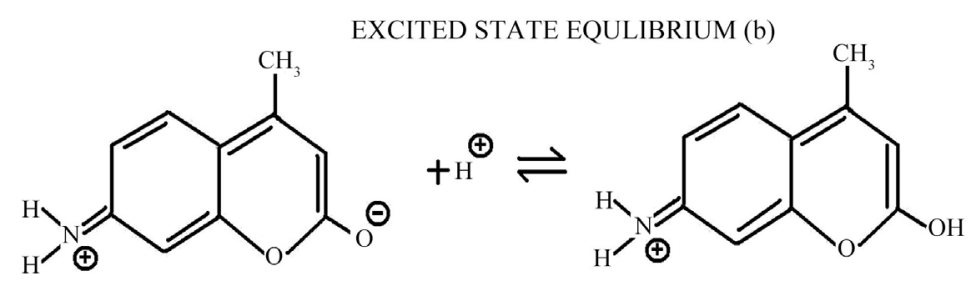

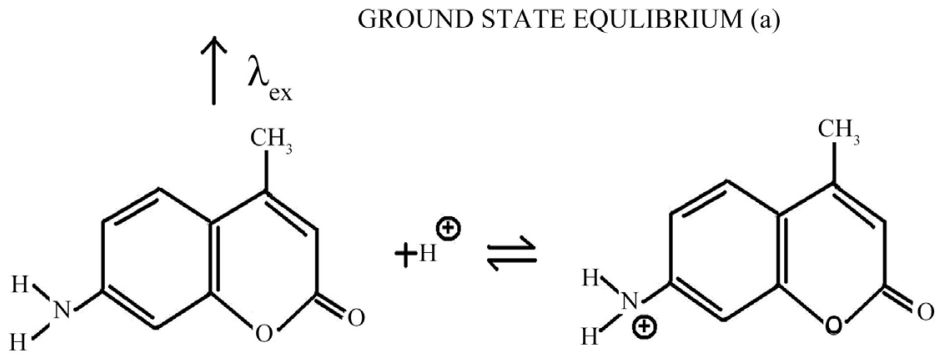

Figure 9. Ground state and excited state equilibria of a C-120 dye in the presence of acid. 
shifts to greenish side as against its usual blue emission. This is because of the abundance of protons in acidified solution which leads to increased protonation at the carbonyl group in the excited state. Due to loss of energy during proton transfer the fluorescence shifts to longer wavelength. This can be used to improve tunability by changing $\mathrm{pH}$ of the solution. As acid catalysed sol-gel process is widely used for preparing host matrices for the laser dyes, the effect of method of preparation on spectroscopic properties of dopant molecules is of great importance as regard to the application of these dye embedded sol-gel glasses as laser materials.

But studied dried C-120 dye doped sol-gel solid glass samples show only single emission peak at $430 \mathrm{~nm}, 432 \mathrm{~nm}$ and $427 \mathrm{~nm}$ prepared by Method I, II and Method III respectively, which gets slightly red shifted with increase in intensity with drying time for the method I and II samples. Thus appearance of carbonyl protonated form cannot be seen in absorbance and has not been observed in fluorescence spectrum of all C-120 sol gel glass samples. As the fluorescence spectra of all C-120 sol-gel glass samples do not have any emission in $478 \mathrm{~nm}$ region, one can say that the corresponding carbonyl protonated species is not formed in solid sol-gel glass samples. Therefore the absorption peaks at $311 \mathrm{~nm}$, $278 \mathrm{~nm}$ and $269 \mathrm{~nm}$ of C-120 in dried sol-gel glass samples prepared by Method I and II can be due to amino-protonated and higher protonated form and cannot be due to carbonyl protonated form.

In case of Method I and Method II samples in present work, after 15 days of drying the local environment of $\mathrm{C}-120$ molecules in glass may be having $\mathrm{HCl}$ containing water and $\mathrm{MeOH}$ surrounding them as the sample is not completely dried. Hence in addition to neutral coumarin form which exists in ground state absorbing at $354 \mathrm{~nm}$, there may be protonated, higher protonated and even some higher protonated species may be present which show absorption peaks in shorter wavelength region of the spectrum. But as the drying time increases the sol-gel glass matrix gets rigidised separating the molecules of C-120 in pores. The molecules of C-120 exist in various forms depending on the environment in pores. During this process of drying and separation, some protonated molecules may be converted into neutral form depending upon the environment in the pores as supported by decrease in OD value of absorption peaks at $311 \mathrm{~nm}, 269$ $\mathrm{nm}$ and $278 \mathrm{~nm}$ as seen from Figure 5. This is supported by observation of increase in OD at $354 \mathrm{~nm}$ peak and increase in FI with drying time with some shift of fluorescence peak wavelength. Also increase in OD at $354 \mathrm{~nm}$ confirms increase in neutral form concentration with drying time. As the dipping time of the sol-gel host samples (Method II) increases the maximum residual solvent containing $\mathrm{HCl}$ coming out from sol-gel glass matrix and therefore existence of neutral form of coumarin dyes is high in longer dipped samples as compared to low dipped glass samples. This automatically reduces the possibility of formation of protonated form with longer dipped matrix samples. This is supported by decrease in OD value of absorption peaks at $311 \mathrm{~nm}, 269 \mathrm{~nm}$ and $278 \mathrm{~nm}$ and increasing in FI at main peak as seen from Figure 7(a), Figure 7(b). Hence an in- 
crease in OD/FI occurs only because of conversion of protonated species into the neutral monomer species. It was also observed that absorption/fluorescence peaks of C-120/sol-gel glass samples (Method I and II) initially were almost same as that of $\mathrm{C}-120 / \mathrm{MeOH}(352 / 429 \mathrm{~nm})$, which is shifted towards longer wavelength after 90 days of drying. In case of samples prepared by method III, the unwanted residual solvent and other chemicals are coming out of the solid during heating the glass sample at high temperature and therefore the environment of dye molecule is only solid $\mathrm{SiO}_{2}$ cage resulting in almost no change (very little change in fluorescence intensity with time) in spectroscopic properties of samples with increasing drying time. The red shift in absorption/fluorescence peak of coumarin containing sol-gel glass samples with respect to its methanolic solution may be the combined effect of increased refractive index of sol-gel compared to methanol, the local environment of the dye molecules in the sol-gel and polar nature of the host [38] [39].

\subsection{Absorption/Fluorescence Properties of Stilbene-3 (STB-3)}

Figures 10(a)-(c) and Figures 11(a)-(c) show the absorption and fluorescence spectra of Stilben-3 (STB-3) dye doped sol-gel glass samples prepared by Method I, Method II and Method III respectively with increasing drying time. It represents the typical behavior of these solids which is observed for all the concentrations of the dye studied in the present work. The shapes of the spectra are similar to those in alcoholic solution suggesting existence of similar forms of dye molecule in the solution and solids.

All STB-3 doped solid glass samples prepared by Method I, II and Method III having number densities of the order of $1015 / \mathrm{cm} 3$ to $1017 / \mathrm{cm} 3$ show single absorption peak peaking at $345 \mathrm{~nm}, 344 \mathrm{~nm}$ and $348 \mathrm{~nm}$ respectively. As the drying time increases there is a decrease in the optical density (OD) value of main absorption peak at $345 \mathrm{~nm}$ and $344 \mathrm{~nm}$ for Method I and Method II samples respectively. But in case of samples prepared by Method III no such change in OD value is observed as drying time increases.

Also slight blue shift $(2 \mathrm{~nm})$ is observed in absorption maximum wavelength after 240 days of time of drying for all three types of STB-3 embedded sol-gel glasses. The Fluorescence Intensity (FI) also decreases with the lapse of time of preparation for Method I and Method II prepared samples, while no change in fluorescence intensity is observed in samples prepared by Method III as the drying time increases as shown in Figure 11(c). However, the observed changes in absorption and fluorescence properties with increasing drying time are very less in samples prepared by Method II as compared to samples prepared by Method I. This observation is similar as that observed in coumarin dyes.

Table 5 lists the absorption properties of STB-3 in sol-gel blocks as well as in methanol with low concentration of the dye (number density of the order of $10^{15}$ per $\left.\mathrm{cm}^{3}\right)$. The absorption wavelength maxima $\left(\lambda_{a}\right)$ for sample prepared by all the three methods are little blue shifted as compared to that in methanol. The extinction coefficient $(\varepsilon)$ of STB3 in solid prepared by Method I and Method II are 
less compared to that in solution, where as in solids prepared by Method III it is more than that in solution. But the order of magnitude of $\varepsilon$ value is same for all the samples.

Table 5. Absorption properties of STB-3/sol-gel glass samples in comparison with STB-3/MeOH.

\begin{tabular}{cccc}
\hline & No. density $\left(\times 10^{15} \mathrm{~cm}^{-3}\right)$ & $\lambda_{a}(\mathrm{~nm})$ & $\varepsilon \times 10^{-4}\left(1 \cdot \mathrm{mole}^{-1} \cdot \mathrm{cm}^{-1}\right)$ \\
\hline STB-3/MeOH & 4.93 & 351 & 5.89 \\
Method I & 8.69 & 345 & 5.16 \\
Method II & 7.32 & 344 & 5.49 \\
Method III & 5.20 & 347 & 5.96 \\
\hline
\end{tabular}

Uncertainty $1 \mathrm{~nm}$ in $\left(\lambda_{a}\right)$.

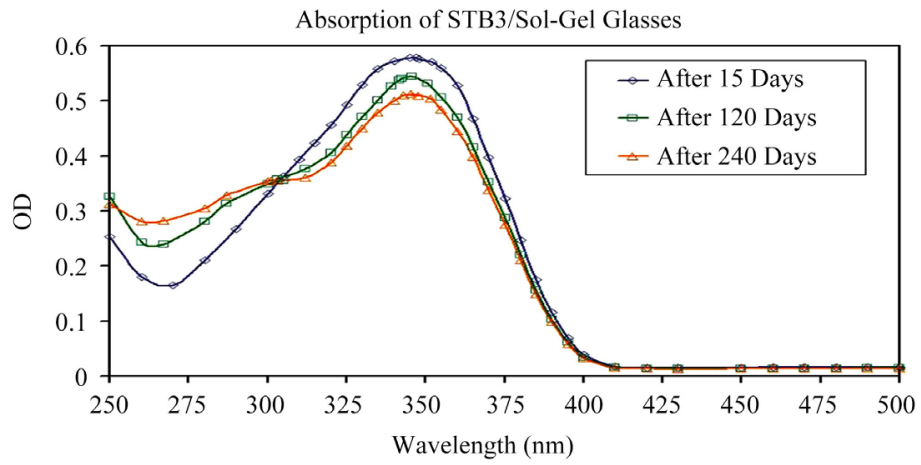

(a)

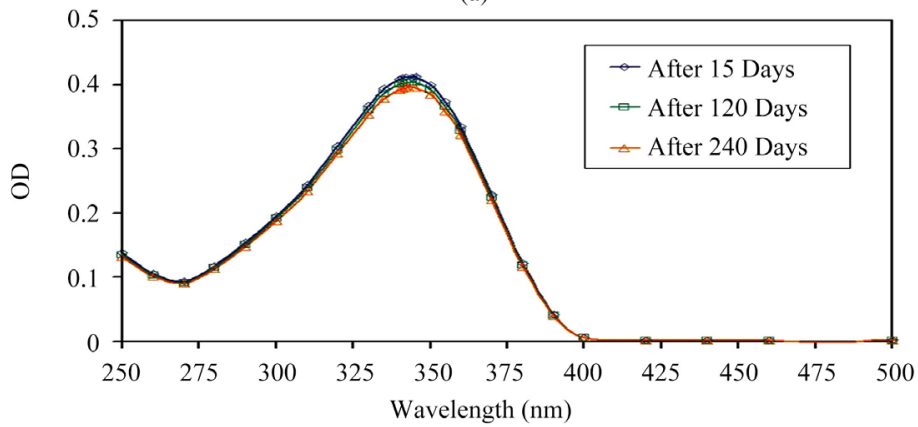

(b)

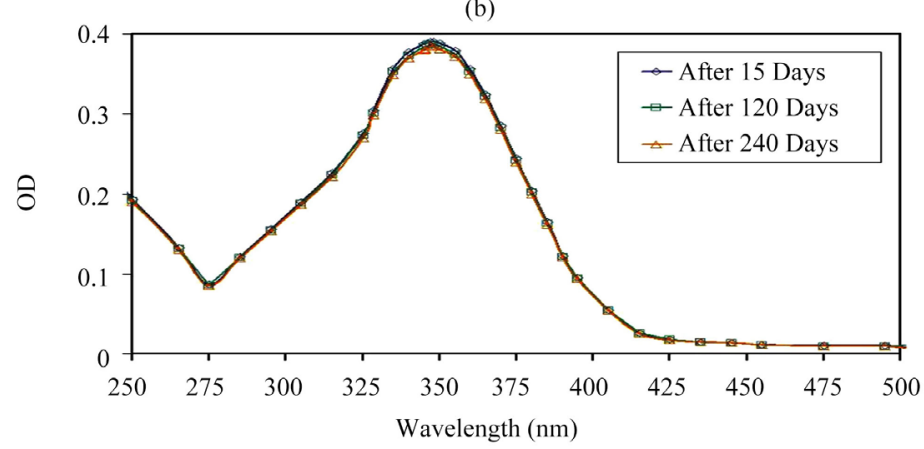

(c)

Figure 10. Absorption spectra of STB-3 containing sol-gel glass sample (a) Method I: (no. density $1.12 \times 10^{16}$ per $\mathrm{cm}^{3}$ ) (b) Method II: (no. density $7.50 \times 10^{15}$ per $\mathrm{cm}^{3}$ ) and (c) Method III; (no. density $6.62 \times 10^{15}$ per $\mathrm{cm}^{3}$ ). 


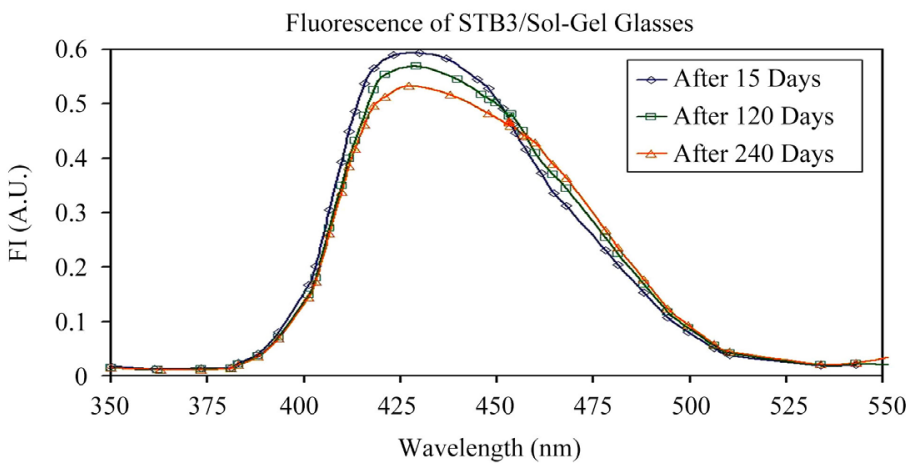

(a)

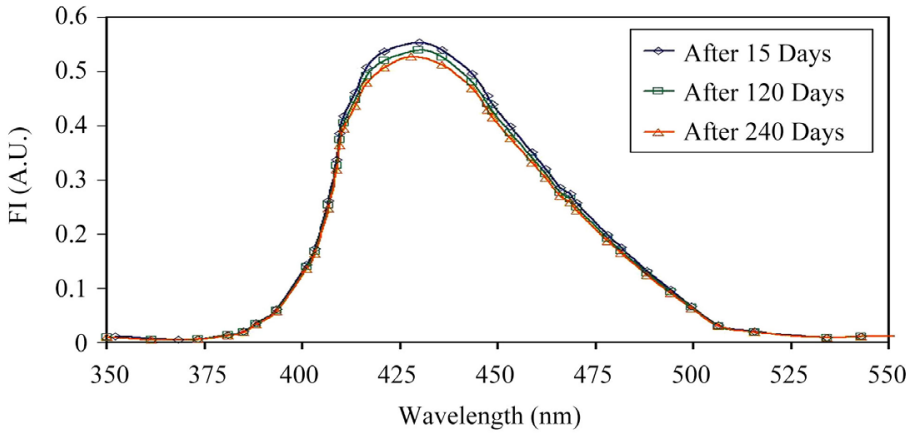

(b)

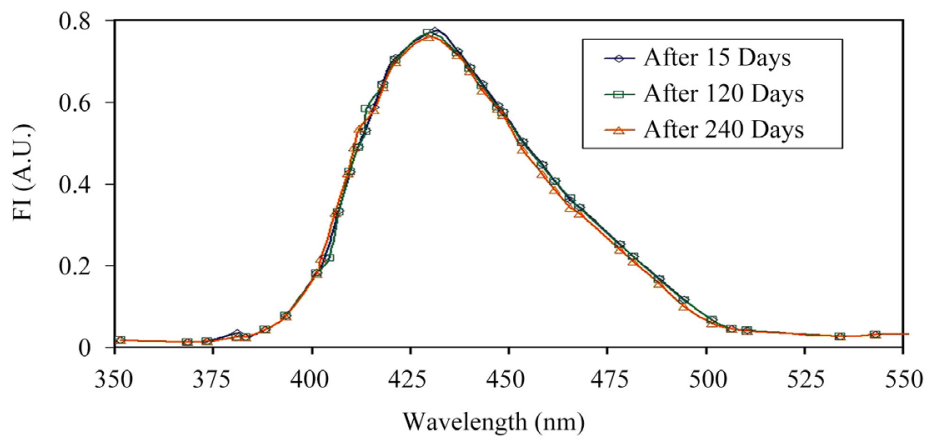

(c)

Figure 11. Fluorescence spectra of STB-3 containing sol-gel glass samples (a) Method I: (no. density $8.52 \times 10^{16}$ per $\mathrm{cm}^{3}$ ), (b) Method II (no. density 6.35 $\times 10^{16}$ per $\mathrm{cm}^{3}$ ) and (c) Method III (no. density $1.32 \times 10^{17}$ per $\mathrm{cm}^{3}$ ).

The changes observed in the fluorescence spectra of solid glass blocks with increasing dye concentrations (number densities of dye molecules of the order of $10^{15}-10^{18}$ per $\mathrm{cm}^{3}$ of the solid) are depicted in Table 6 . The fluorescence wavelength $\left(\lambda_{f}\right)$ of the dye doped solids is from $430-434 \mathrm{~nm}$ which is slightly blue shifted compared to that in alcoholic solution (435 nm). The FWHM increases initially as the concentration of the dye increases but decreases again for the higher number density samples. The Fluorescence Intensity (FI) also first increases and then decreases as the concentration of the dye in solid increases which is due to concentration quenching [37] [38] [39] [40].

Samples prepared by method I and II show that the FI values are lower than those observed for samples prepared by Method III. This may be due to the presence of some residuals along with acid in Method I and Method II samples 
whereas most residual solvent/chemicals are coming out from the Method III samples during heating. The absorption and fluorescence spectra suggest the existence of single emitting species.

The absorption and fluorescence properties of STB-3 in sol-gel glass samples after drying for 240 days along with that in methanol are summarized in Table 7 and Table 8 respectively. The spectroscopic properties have been compared on the basis of following parameters namely absorption wavelength maximum $\left(\lambda_{a}\right)$, extinction coefficient $(\varepsilon)$, fluorescence wavelength maximum $\left(\lambda_{f}\right)$, fluorescence quantum yield $\left(\Phi_{f}\right)$, fluorescence lifetime $\left(\tau_{f}\right)$ and nonradiative deactivation rate constant $\left(K_{n r}\right)$.

Table 6. Fluorescence properties of STB-3/sol-gel glass samples with different concentrations.

\begin{tabular}{|c|c|c|c|}
\hline No. density $\left(\mathrm{cm}^{-3}\right)$ & $\lambda_{f}(\mathrm{~nm})$ & FWHM $\left(\mathrm{cm}^{-1}\right)$ & FI (A.U.) \\
\hline \multicolumn{4}{|c|}{ Method I } \\
\hline $6.78 \times 10^{15}$ & 431 & 875 & 0.20 \\
\hline $4.84 \times 10^{16}$ & 431 & 975 & 0.45 \\
\hline $8.52 \times 10^{16}$ & 431 & 1265 & 0.59 \\
\hline $3.80 \times 10^{17}$ & 432 & 1386 & 0.82 \\
\hline $8.56 \times 10^{17}$ & 433 & 1274 & 0.69 \\
\hline $2.49 \times 10^{18}$ & 434 & 1170 & 0.49 \\
\hline $5.51 \times 10^{18}$ & 434 & 919 & 0.32 \\
\hline \multicolumn{4}{|c|}{ Method II } \\
\hline $4.96 \times 10^{15}$ & 430 & 812 & 0.30 \\
\hline $5.63 \times 10^{16}$ & 430 & 990 & 0.52 \\
\hline $9.51 \times 10^{16}$ & 431 & 1206 & 0.78 \\
\hline $3.78 \times 10^{17}$ & 431 & 1379 & 0.90 \\
\hline $7.96 \times 10^{17}$ & 432 & 1219 & 0.75 \\
\hline $2.71 \times 10^{18}$ & 432 & 984 & 0.60 \\
\hline $6.31 \times 10^{18}$ & 433 & 829 & 0.42 \\
\hline \multicolumn{4}{|c|}{ Method III } \\
\hline $5.18 \times 10^{15}$ & 432 & 753 & 0.51 \\
\hline $3.94 \times 10^{16}$ & 432 & 912 & 0.68 \\
\hline $7.62 \times 10^{16}$ & 432 & 1086 & 0.88 \\
\hline $5.91 \times 10^{17}$ & 433 & 1320 & 0.97 \\
\hline $9.43 \times 10^{17}$ & 433 & 1152 & 0.85 \\
\hline $3.29 \times 10^{18}$ & 434 & 1037 & 0.72 \\
\hline $4.44 \times 10^{18}$ & 434 & 896 & 0.51 \\
\hline
\end{tabular}

Uncertainty $1 \mathrm{~nm}$ in $\left(\lambda_{f}\right) ; 0.05$ in (FI). 
Table 7. Changes in Absorption properties of STB-3/sol-gel glass solids with time in comparison with STB-3/MeOH.

\begin{tabular}{|c|c|c|c|c|}
\hline \multirow{3}{*}{ STB-3/MeOH } & \multirow{2}{*}{\multicolumn{2}{|c|}{$\begin{array}{c}\lambda_{a} \text { at main peak }(\mathrm{nm}) \\
351\end{array}$}} & \multirow{2}{*}{\multicolumn{2}{|c|}{$\begin{array}{c}\varepsilon \times 10^{-4}\left(1 \cdot \mathrm{mole}^{-1} \cdot \mathrm{cm}^{-1}\right) \\
5.89\end{array}$}} \\
\hline & & & & \\
\hline & a & $\mathrm{b}$ & a & $\mathrm{b}$ \\
\hline Method I & 345 & 343 & 5.16 & 4.66 \\
\hline Method II & 344 & 342 & 5.49 & 5.38 \\
\hline Method III & 348 & 346 & 5.96 & 5.92 \\
\hline
\end{tabular}

Uncertainty $1 \mathrm{~nm}$ in $\left(\lambda_{a}\right)$. a: Values after 15 days. b: Values after 240 days.

Table 8. Changes in fluorescence properties of STB-3/sol-gel glass solids with time in comparison with STB-3/MeOH.

\begin{tabular}{cccccccccc}
\hline & \multicolumn{2}{c}{$\lambda_{f}(\mathrm{~nm})$} & \multicolumn{2}{c}{$\Phi_{f}$} & \multicolumn{2}{c}{$\tau_{f}(\mathrm{~ns})$} & \multicolumn{2}{c}{$\begin{array}{c}K_{n r} \times 10^{9} \\
\mathbf{0 . 1 1 6}\end{array}$} \\
\cline { 2 - 10 } STB-3/MeOH & \multicolumn{2}{c}{$\mathbf{4 3 5}$} & \multicolumn{2}{c}{$\mathbf{0 . 8 0}$} & \multicolumn{2}{c}{$\mathbf{1 . 2}$} & \multicolumn{2}{c}{ a } \\
\cline { 2 - 10 } & $\mathrm{a}$ & $\mathrm{b}$ & $\mathrm{a}$ & $\mathrm{b}$ & $\mathrm{a}$ & $\mathrm{b}$ & $\mathrm{a}$ & $\mathrm{b}$ \\
\hline Method I & 431 & 429 & 0.65 & 0.60 & 1.12 & 1.09 & 0.312 & 0.367 \\
Method II & 430 & 428 & 0.74 & 0.71 & 1.16 & 1.14 & 0.224 & 0.254 \\
Method III & 432 & 431 & 0.85 & 0.84 & 1.42 & 1.42 & 0.106 & 0.113 \\
\hline
\end{tabular}

Uncertainty $1 \mathrm{~nm}$ in $\left(\lambda_{f}\right) ; 0.05$ in $\left(\Phi_{f}\right), 0.05 \mathrm{~ns}$ in $\left(\tau_{f}\right)$. a: Values after 15 days. b: Values after 240 days.

It can be seen from Table 7 and Table 8 that the properties of the dye in sol-gel are influenced by the method of preparation. The fluorescence quantum yield $\left(\Phi_{f}\right)$ and fluorescence lifetime $\left(\tau_{f}\right)$ illustrate the changes in the rates of radiative and non-radiative decay. The $\Phi_{f}$ value of STB-3 in Method I samples is moderate $(0.65)$ and $\tau_{f}$ is little less than to that in alcoholic solution, consequently the rate of nonradiative decay is greater in case of these samples. The $\Phi_{f}$ of STB-3 in Method II is high (0.74) and $\tau_{f}$ is comparable that in alcoholic solution. The quantum yield and fluorescence lifetime of STB-3/sol-gel glass solids prepared by Method I and Method II showed slight reduction in values after 240 days, where as nonradiative deactivation rate constant $\left(K_{n r}\right)$ showed increase in value after 240 days. This increase in $K_{n r}$ values is maximum in Method I samples, moderate in Method II samples and minimum in Method III samples.

In case of samples prepared by Method III the $\Phi_{f}$ and $\tau_{f}$ are little higher than that in solution. The value of $K_{n r}$ is least in Method III samples compared to the other two methods. The quantum yield, fluorescence lifetime and nonradiative deactivation rate constant of STB-3/sol-gel glass solids prepared by Method III was found to remain almost unchanged after a period of 240 days. This may be due to no degradation in dye as the environment inside matrix is totally inert; as the case in studied coumarin dyes. The lifetime values in STB3 dye are very short compared to that of coumarins studied in the present work. Thus the spectroscopic properties of samples prepared by Method III are superior to those prepared by other two methods. The single lifetime values in the range of $1.12-1.42$ ns of STB-3 in these samples are an indication of the existence of a single fluo- 
rescent species.

\subsection{Comparison between C-120 and Stilbene-3 (STB-3) in Sol-Gel Glass}

For all studied of coumarin-120 (C-120) dye doped and Stilbene-3 (Stileben-3) dye doped glass samples, for all three methods; the extinction coefficient $(\varepsilon)$ at the longest absorption peak is least for C-120 is highest for method III samples than the Method I and Method II samples where as there is not much difference in extinction coefficient $(\varepsilon)$ for STB-3 doped samples in all three methods. This photophysical behavior of 7-aminocoumarin derivatives in acid catalyzed sol-gel glass samples is very different from those in alcoholic solutions due to solute/solvent or matrix hydrogen bond interactions, which depend on alkylation degree of amino group of dye and this alkylation degree of amino group of C-120. Our earlier report of Rhodamine B (Rh-B) [58] Coumarin-1 (C-1) and Coumarin-2 (C-2) [40] shows the degradation in photophysical properties with increasing drying time. C-120 dye doped sol-gel matrix shows enhanced photophysical properties with increasing time. This may be because of the substitution at the 7-position in the molecular structure of coumarin dye. C-120 dye is having least interaction with the residuals in the matrix while C-1 and C-2 with alkyl groups have more interaction degrading the sample more.

C-120 dye in Method I and Method II samples also contain aminoprotonated form which is nonfluorescent. The formation of such nonfluorescent species is not useful for lasing activity. While coumarin dyes show almost no degradation in the samples prepared by Method III with very good photophysical properties as compared to those observed in $\mathrm{MeOH}$. Where as STB-3 dye in all Method-I, Method-II and Method-III samples shows excellent fluorene properties with no degradation with time.

\section{Conclusions}

C-120 and STB-3 were successfully embedded in $\mathrm{HCl}$ catalyzed sol-gel glasses prepared by all the three different methods. The spectroscopic properties of the dye have been found to be highly dependent on the method of dye trapping.

1) In addition to usual molecular form of C-120 $\left(\lambda_{a}=352 \mathrm{~nm}, \lambda_{f}=430 \mathrm{~nm}\right)$ that exists in methanol, the dye has been found to exist in two new and distinct molecular forms mentioned as amino-protonated or higher protonated forms $\left(\lambda_{a}\right.$ $=311 \mathrm{~nm}, 278 \mathrm{~nm}, 269 \mathrm{~nm}$ and non-fluorescent) in the dried state of samples prepared by Method I and II. The acidic environment of the cage, created by $\mathrm{HCl}$ used as catalyst, and unwanted residual molecules, produced even in the initial stage of drying are responsible for the protonation at the amino group in sol-gel samples prepared by Method I and II respectively. But it has been identified that the neutral species increase at the cost of protonated form with time of drying for Method I and II prepared sol-gel glass samples. Thus together with environment of dye molecules, drying of sol-gel samples also plays an important 
role.

2) The photophysical behavior of C-120 in sol-gel host matrix prepared by Method I is the same as that in the Method II samples with better enhancement in photophysical properties with drying time than that of Method II samples.

3) On the other hand, the spectroscopic behaviour of C-120 in Method III sol-gel samples is similar to that of methanolic dye solution. The non-acidic environment and absence of unwanted residual species in the pores are responsible factors for the non-existance of protonated and any other unwanted residuals. The absence of any degradation in absorption/fluorescence properties of C-120 in these samples with drying time confirms that the dye molecules are very stable in these solids.

4) The comparative study of C-120 in sol-gel matrices prepared by all the three methods shows that the photophysical performance of dye in Method III sol-gel samples is better than that in the Method I and II samples resulting in enhanced longevity and photophysical properties in sol-gel matrix.

5) The STB-3 in sol-gel matrices prepared by all the three methods shows that the excellent photophysical properties in sol-gel matrix.

\section{Conflicts of Interest}

The authors declare no conflicts of interest regarding the publication of this paper.

\section{References}

[1] Sorokin, P.P. and Landkard, J.R. (1966) Stimulated Emission Observed from an Organic Dye, Chloro-Aluminum Phthalocyanine. IBM Journal of Research and Development, 10, 162-163. https://doi.org/10.1147/rd.102.0162

[2] Schafer, F.P., Schmidt, W. and Marth, K. (1967) New Dye Lasers Covering the Visible Spectrum. Physics Letters A, 24, 280-281.

https://doi.org/10.1016/0375-9601(67)90437-9

[3] Peterson, O.G., Tuccio, S.A. and Snavely, B.B. (1970) cw Operation of an Organic Dye Solution Laser. Applied Physics Letters, 17, 245-247. https://doi.org/10.1063/1.1653384

[4] Maeda, M. (1984) Laser Dyes. Academic Press, Cambridge.

[5] Schafer, F.P. (1990) Dye Lasers. Springer Verlag, Berlin.

[6] Pavlopoulos, T.G., Shah, M. and Boyer, J.H. (1989) Efficient Laser Action from 1,3,5,7,8-pentamethylpyrromethene- $\mathrm{BF}_{2}$ Complex and Its Disodium 2,6-disulfonate Derivative. Optics Communications, 70, 425-427. https://doi.org/10.1016/0030-4018(89)90144-2

[7] Pavlopoulos, T.G., Boyer, J.H., Shah, M., Thangaraj, K. and Soong, M.L. (1990) Laser Action from 2, 6, 8-Position Trisubstituted 1,3,5,7-tetramethylpyrromethene- $\mathrm{BF}_{2}$ Complexes: Part 1. Applied Optics, 29, 3885-3886. https://doi.org/10.1364/AO.29.003885

[8] Bornemann, R., Lemmer, U. and Thiel, E. (2006) Continuous-Wave Solid-State Dye Laser. Optics Letters, 31, 1669-1671.

[9] Orel, B., Groselj, N., Krasovec, U.O., Bukovec, P. and Reisfeld, R. (1998) Gasoch- 
romic Effect of Palladium Doped Peroxopolytungstic Acid Films Prepared by the Sol-Gel Route. Sensors and Actuators B: Chemical, 50, 234-245. https://doi.org/10.1016/S0925-4005(98)00241-X

[10] Reisfeld, R., Shamrakov, D. and Jorgensen, C.K. (1994) Photostable Solar Concentrators Based on Fluorescent Glass Films. Solar Energy Materials and Solar Cells, 33, 417-427. https://doi.org/10.1016/0927-0248(94)90002-7

[11] Aegerter, M.A., Mehrota, R.C., Oehme, I., Reisfeld, R., Sakka, S., Wolfbeis, O. and Kørgensen, C.K. (1996) Optical and Electronic Phenomena in Sol-Gel Glasses and Modern Applications. Vol. 85, Springer Verlag, Berlin, Heidelberg, 51.

[12] Reisfeld, R. and Shamrakov, D. (1996) Reversible Optical Sensor for in Situ Determination of Heavy Metal Impurities in the Environment. Sensors and Materials, 8 , 439-443.

[13] Sorek, Y., Reisfeld, R., Finkelstein, I. and Ruschin, R. (1995) Light Amplification in a Dye-Doped Glass Planar Waveguide. Applied Physics Letters, 66, 1169-1171. https://doi.org/10.1063/1.113846

[14] Reisfeld, R., Minti, H., Eyal, M. and Chernyak, V. (1993) Nonlinear Properties of Semiconductor Quantum Dots and Organic Molecules in Glasses, Prepared by the Sol Gel Method. Journal of Nonlinear Optical Physics, 5, 339-360.

[15] Reisfeld, R. (1996) New Materials for Nonlinear Optics. In: Reisfeld, R. and Jorgensen, C.K., Eds., Optical and Electronic Phenomena in Sol-Gel Glasses and Modern Applications, Vol. 85, Springer Verlag, Berlin, Heidelberg, 99-147.

https://doi.org/10.1007/BFb0111489

[16] Strek, W., Sokolnicki, J., Legendziewicz, J., Maruszewski, K., Nissen, B., Reisfeld, R. and Pavich, T (1999) Optical Properties of Eu(III) Chelates Trapped in Silica Gel Glasses. Optical Materials, 13, 41-48. https://doi.org/10.1016/S0925-3467(99)00009-9

[17] Saraidarov, T., Reisfeld, R. and Pietraszkiewicz, M. (2000) Luminescent Properties of Silica and Zirconia Xerogels Doped with Europium(III) Salts and Europium(III) Cryptate 3,3'-biisoquinoline-22'-dioxide. Chemical Physics Letters, 330, 515-520. https://doi.org/10.1016/S0009-2614(00)01059-9

[18] Reisfeld, R. (1996) Lasers Based in Sol-Gel Technology. In: Reisfeld. R. and Jorgensen. C.K., Eds., Optical and Electronic Phenomena in Sol-Gel Glasses and Modern Applications, Vol. 85, Springer Verlag, Berlin, Heidelberg, 215-233.

[19] Reisfeld, R. and Seybold, G. (1991) Stable Solid-State Tunable Lasers in the Visible. Journal of Luminescence, 48-49, 898-900. https://doi.org/10.1016/0022-2313(91)90266-X

[20] Reisfeld, R., Yariv, E. and Minti, H. (1997) New Developments in Solid State Lasers. Optical Matherials, 8, 31-36. https://doi.org/10.1016/S0925-3467(97)00036-0

[21] Reisfeld, R. and Yariv, E. (2000) Porous Glasses as a Host for Solid State Tunable Lasers in the Visible as a Means for Fluorescence Diagnostics and Photodynamic Therapy. Optica Applicata, 30, 481-490.

[22] Chemyak, V., Reisfeld, R., Gvishi, R. and Venezky, D. (1990) Oxazine-170 in Sol-Gel Glass and PMMA Films as a Reversible Optical Waveguide Sensor for Ammonia and Acids. Sensors and Materials, 2, 117-126.

[23] Lam, K.S. and Lo, D. (1998) Lasing Behavior of Sol-Gel Silica Doped with UV Laser Dyes. Applied Physics B, 66, 427-430. https://doi.org/10.1007/s003400050413

[24] Fukuda, M. and Mito, K. (2000) Laser Oscillation of Energy Transfer Solid-State Dye Laser with a Thin-Film Ring Resonator. Japanese Journal of Applied Physics, 39, 3470-3471. https://doi.org/10.1143/JAP.39.3470 
[25] Weissbeck, A., Langhoff, H. and Beck, A. (1995) Lasing and Fluorescence Properties of Dye-Doped Xerogel. Applied Physics B, 61, 253-255. https://doi.org/10.1007/BF01082044

[26] Srinivasan, R. (1969) New Materials for Flash-Pumped Organic Lasers. IEEE Journal of Quantum Electronics, 5, 552-553.

[27] Ye, C., Lam, K.S., Lam, S.K. and Lo, D. (1997) Dye-Doped Sol-Gel Derived Silica Laser Tunable from 352nm to 387nm. Applied Physics B, 65, 109-111. https://doi.org/10.1007/s003400050257

[28] Lam, S.K., Zhu, X.L. and Lo, D. (1999) Single Longitudinal Mode Lasing of Coumarin-Doped Sol-Gel Silica Laser. Applied Physics B, 68, 1151-1153. https://doi.org/10.1007/s003400050760

[29] Arbeloa, T.L., Arbeloa, F.L., Tapia, M.J. and Arbeloa, I.L. (1993) Hydrogen-Bonding Effect on the Photophysical Properties of 7-Aminocoumarin Derivatives. Journal of Physical Chemistry, 97, 4704-4707. https://doi.org/10.1021/j100120a024

[30] Jones, G., Jackson, W.R. and Halpern, A.M. (1980) Medium Effects on Fluorescence Quantum Yields And Lifetimes for Coumarin Laser Dyes. Chemical Physics Letters, 72, 391-395. https://doi.org/10.1016/0009-2614(80)80314-9

[31] Jones, G., Jackson, W.R., Yoo Choi, C. and Bergmark, W.R. (1985) Solvent Effects on Emission Yield and Lifetime for Coumarin Laser Dyes. Requirements for a Rotatory Decay Mechanism. Journal of Physical Chemistry, 89, 294-300. https://doi.org/10.1021/j100248a024

[32] Gustavsson, T., Cassara, L., Gulbinas, V., Mialocq, J.C., Pommeret, S., Sorgius, M. and van der Meulen, P. (1998) Femtosecond Spectroscopic Study of Relaxation Processes of Three Amino-Substituted Coumarin Dyes in Methanol and Dimethyl Sulfoxide. Journal of Physical Chemistry A, 102, 4229-4245.

https://doi.org/10.1021/jp980282d

[33] Kunjappu, J.T. (1993) Photophysical Properties of Five Laser Dyes (C120, Cl, C102, $\mathrm{C} 1 \mathrm{~F}$ and $\mathrm{C} 153$ ) in Homogeneous, Surfactant and Membrane Media. Journal of Photochemistry and Photobiology A: Chemistry, 71, 269-273. https://doi.org/10.1016/1010-6030(93)85009-W

[34] Costela, A., Gercia-Moreno, I., Barosso, J. and Sastre, R. (1998) Studies on Laser Action from Polymeric Matrices Doped with Coumarin 503. Applied Physics B, 67, 167-173. https://doi.org/10.1007/s003400050489

[35] Suratwala, T., Gardlund, Z., Davidson, K., Uhlmann, D.R., Watson, J., Bonilla, S. and Peyghambarian, N. (1998) Silylated Coumarin Dyes in Sol-Gel Hosts. 2. Photostability and Sol-Gel Processing. Chemistry of Materials, 10, 199-209. https://doi.org/10.1021/cm970340s

[36] Deshpande, A.V. and Namdas, E.B. (2000) Correlation between Lasing and Photophysical Performance of Dyes in Polymethylmethacrylate. Journal of Luminescence, 91, 25-31. https://doi.org/10.1016/S0022-2313(00)00210-6

[37] Costela, A., Gercia-Moreno, I., Barosso, J. and Sastre, R. (1998) Laser Performance of Coumarin 540A Dye Molecules in Polymeric Host Media with Different Viscosities: From Liquid Solution to Solid Polymer Matrix. Journal of Applied Physics, 83, 650-660. https://doi.org/10.1063/1.366755

[38] Deshpande, A.V. and Panhalkar, R.R. (2002) Spectroscopic Properties of Coumarin 2 in $\mathrm{HCl}$ and $\mathrm{HNO}_{3}$ Catalysed Sol-Gel Glasses. Journal of Luminescence, 96, 185-193. https://doi.org/10.1016/S0022-2313(01)00218-6

[39] Deshpande, A.V. and Kumar, U. (2006) Molecular Forms of Coumarin-307 in Sol-Gel 
Glasses. Journal of Fluorescence, 16, 679-687. https://doi.org/10.1007/s10895-006-0109-5

[40] Deshpande, A.V., Jathar, L.V. and Rane, J.R. (2008) Effect of Matrix Treatment on Spectro-Scopic Properties of $\mathrm{HCl}$ Catalysed Sol-Gel Glasses Containing Coumarin Laser Dyes. Journal of Fluorescence, 19, Article No. 607. https://doi.org/10.1007/s10895-008-0451-x

[41] Del Monte, F., Mackenzie, J.D. and Levy, D. (2000) Rhodamine Fluorescent Dimers Adsorbed on the Porous Surface of Silica Gels. Langmuir, 16, 7377-7382. https://doi.org/10.1021/la000540+

[42] Del Monte, F. and Levy, D. (1999) Identification of Oblique and Coplanar Inclined Fluorescent J-Dimers in Rhodamine 110 Doped Sol-Gel-Glasses. Journal of Physical Chemistry B, 103, 8080-8086. https://doi.org/10.1021/jp991491g

[43] Del Monte, F. and Levy, D. (1998) Formation of Fluorescent Rhodamine B J-Dimers in Sol-Gel Glasses Induced by the Adsorption Geometry on the Silica Surface. Journal of Physical Chemistry B, 102, 8036-8041. https://doi.org/10.1021/jp982396v

[44] Leveau, B., Herlet, N., Livage, J. and Sanchez Chem, C. (1993) Optical Properties of a Near-Infrared Dye Laser Incorporated Inside Sol-Gel Matrices. Chemical Physics Letters, 206, 15-20. https://doi.org/10.1016/0009-2614(93)85509-M

[45] Del Monte, F. and Levy, D. (1995) Near-Infrared Dyes Encapsulated in Sol-Gel Matrixes. Chemistry of Materials, 7, 292-298. https://doi.org/10.1021/cm00050a010

[46] Levy, D. and Avnir, D. (1988) Effects of the Changes in the Properties of Silica Cage along the Gel/Xerogel Transition on the Photochromic Behavior of Trapped Spiropyrans. Journal of Physical Chemistry, 92, 4734-4738.

https://doi.org/10.1021/j100327a035

[47] Narang, U. and Bright, F. (1996) Conformational Flexibility of 1,3-Bis(1-Pyrenyl)Propane Throughout the Sol-Gel to Xerogel Process. Chemistry of Materials, 8, 1410-1414. https://doi.org/10.1021/cm960040v

[48] Innozenci, P., Kozuka, H. and Yoko, T. (1997) Fluorescence Properties of the Ru(bpy) ${ }^{2+}$ Complex Incorporated in Sol-Gel-Derived Silica Coating Films. Journal of Physical Chemistry B, 101, 2285-2291. https://doi.org/10.1021/jp970004z

[49] Martini, I., Hartland, G.V. and Kamat, P.V. (1997) Ultrafast Photophysical Investigation of Cresyl Violet Aggregates Adsorbed onto Nanometer-Sized Particles of $\mathrm{SnO}_{2}$ and $\mathrm{SiO}_{2}$. Journal of Physical Chemistry $B, 101,4826-4830$. https://doi.org/10.1021/jp9702964

[50] Innocenzi, P., Kozuka, H. and Yoko, T. (1996) Dimer-to-Monomer Transformation of Rhodamine 6G in Sol-Gel Silica Films. Journal of Non-Crystalline Solids, 201, 26-36. https://doi.org/10.1016/0022-3093(95)00620-6

[51] Lo, D., Parris, J.E. and Lawless, J.L. (1993) Laser and Fluorescence Properties of Dye-Doped Sol-Gel Silica from 400nm to 800nm. Applied Physics B, 56, 385-390. https://doi.org/10.1007/BF00324537

[52] Singh, S., Kanetkar, V.R., Sridhar, G., Muthuswamy, V. and Raja, K. (2003) Solid-State Polymeric Dye Lasers. Journal of Luminescence, 101, 285-291. https://doi.org/10.1016/S0022-2313(02)00571-9

[53] Eastman Kodak Company (1987) Kodak Laser Dyes. Laboratory and Research Products Division. Eastman Kodak Company, Rochester.

[54] Kodak Optical Products (1990) Kodak Publication.

[55] Rahn, M.D. and King, T.A. (1995) Comparison of Laser Performance of Dye Molecules in Sol-Gel, Polycom, Ormosil, and Poly(Methyl Methacrylate) Host Media. 
Applied Optics, 34, 8260-8271. https://doi.org/10.1364/AO.34.008260

[56] Crosby, G.A. and Demas, J.N. (1971) Measurement of Photoluminescence Quantum Yields. Journal of Physical Chemistry, 75, 991-1024.

https://doi.org/10.1021/j100678a001

[57] Drexhage, K.H. (1989) Structure and Properties of Laser Dyes. In: Schafer, F.P., Ed., Dye Lasers, Springer, New York, 172-175.

[58] Deshpande, A.V. and Kumar, U. (2002) Effect of Method of Preparation on Photophysical Properties of Rh-B Impregnated Sol-Gel Hosts. Journal of Non-Crystalline Solids, 306, 149-159. https://doi.org/10.1016/S0022-3093(02)01054-2

[59] Bozkurta, E. and Onganer, Y. (2018) Photophysical Features of Coumarin 120 in Reverse Micelles. Journal of Molecular Structure, 1173, 490-497. https://doi.org/10.1016/j.molstruc.2018.07.019

[60] Kasim, M. and Husain, S. (2019) Computational and Experimental Spectroscopic Study of Coumarin 440. Invertis Journal of Science \& Technology, 12, 8-11. https://doi.org/10.5958/2454-762X.2019.00002.7

[61] Zhou, Z., Fan, R., Chen, Z., Xu, X., Jia, T. and Chen, D. (2017) Research of Solid-State Laser Based on Pre-Polymerization PMMA Polymer Doped with Laser Dye. In: Frontiers in Optics 2017, OSA Technical Digest, Optical Society of America, Washington DC. https://doi.org/10.1364/FIO.2017.JTu2A.15

[62] Jathar, L.V., Achalawat, D.G., Rane, J.R., Deshpande, A.V. and Wagle, S.M. (2016) Photo-Physical Properties of Stilbine-3 (STB-3) Laser Dyes Embedded in Sol-Gel Glasses. New Journal of Glass and Ceramics, 6, 64-74.

https://doi.org/10.4236/njgc.2016.64008 